Rowan University

Rowan Digital Works

Theses and Dissertations

6-19-2019

\title{
Validity of a functional assessment for smoking treatment recommendations questionnaire
}

Connor Andrew Burrows

Rowan University

Follow this and additional works at: https://rdw.rowan.edu/etd

Part of the Psychiatry and Psychology Commons

\section{Recommended Citation}

Burrows, Connor Andrew, "Validity of a functional assessment for smoking treatment recommendations questionnaire" (2019). Theses and Dissertations. 2691.

https://rdw.rowan.edu/etd/2691

This Thesis is brought to you for free and open access by Rowan Digital Works. It has been accepted for inclusion in Theses and Dissertations by an authorized administrator of Rowan Digital Works. For more information, please contact graduateresearch@rowan.edu. 


\title{
VALIDITY OF A FUNCTIONAL ASSESSMENT FOR SMOKING TREATMENT RECOMMENDATIONS QUESTIONNAIRE
}

\author{
by \\ Connor A. Burrows
}

\author{
A Thesis \\ Submitted to the \\ Department of Psychology \\ College of Science and Mathematics \\ For the degree of \\ Master of Arts in Clinical Psychology \\ at \\ Rowan University \\ June 3, 2019
}

Thesis Committee Chair: Bethany Raiff, Ph.D. 



\section{Acknowledgements}

I would like to express my deep thanks to Dr. Bethany Raiff for her wonderful mentorship and guidance throughout the course of this project. I would also like to thank Dr.

Kimberly Kirby, Dr. Michelle Soreth, and Dr. Georita Frierson for their insight and input during

the revision of this document. Finally, I would like to express gratitude to Dr. Jesse Dallery and

Dr. Sunny Kim for their work in generating the questions contained with the Functional

Assessment Questionnaire for Smoking Treatment Recommendations and for guidance related to data analyses respectively. This document would not exist without their collective effort. 


\author{
Abstract \\ Connor Burrows \\ VALIDITY OF A FUNCTIONAL ASSESSMENT FOR SMOKING TREATMENT \\ RECOMMENDATIONS QUESTIONNAIRE \\ 2018-2019 \\ Bethany Raiff, Ph.D. \\ Master of Arts in Clinical Psychology
}

Smoking is the leading cause of preventable death in the United States and imposes a substantial economic cost. Despite the well-established potential harm, relapse rates remain high during quit attempts. In the realm of applied behavior analysis, functional assessment has long been recognized as a reliable method to increase effectiveness of treatments for a variety of problem behaviors. Functional assessment may aid in designating targeted treatment for smokers based on the maintaining function(s) of the behavior. The current study $(\mathrm{N}=414)$ sought to assess the reliability and validity of the Functional Assessment of Smoking for Treatment Recommendations (FASTR) and provide preliminary evidence towards a hypothesized factor structure. The full FASTR included five subscales derived from the field of functional behavior assessment: 1) Automatic Positive Reinforcement, 2) Social Positive Reinforcement, 3) Automatic Negative Reinforcement, 4) Social Negative Reinforcement, and 5) Antecedent Stimuli. The full battery of subscales was found to be adequately reliable and valid, with overall sample reliability coefficients ranging from $\alpha=0.69$ to $\alpha=0.90$. Confirmatory factor analysis of the 5-factor model produced acceptable fit indices $(\mathrm{CFI}=0.908, \mathrm{TLI}=0.896, \mathrm{RMSEA}=0.059$, SRMR $=0.071)$. A 5-factor model performed favorably across several fit indices, providing preliminary validity. Further research should aim to replicate the observed factor structure in other samples and establish the clinical utility of the FASTR. 


\section{Table of Contents}

List of Figures . 


\section{List of Figures}

Figures $\quad$ Page

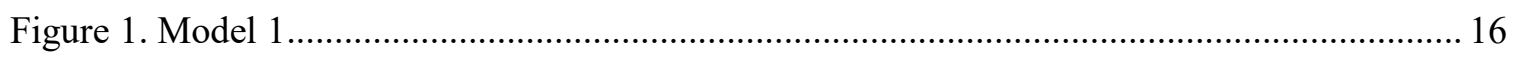

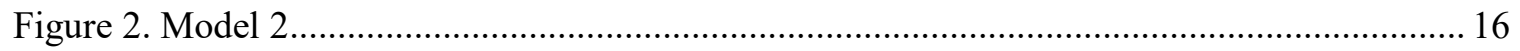




\section{List of Tables}

Tables $\quad$ Page

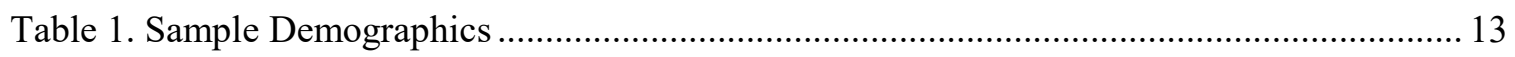

Table 2. Functional Assessment for Smoking Treatment Recommendations (FASTR) ............... 14

Table 3. Scale Intercorrelations and Cronbach's Alpha for the Modified 5-factor model............. 18

Table 4. Factor and Item Error Covariances of the Modified 5-Factor Model .............................. 19

Table 5. Correlations Between Modified FASTR Subscales and FTND Scores ...........................20

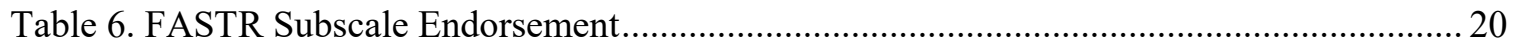




\section{Chapter 1}

\section{Introduction}

Tobacco use is the leading cause of preventable death in the United States and accounts for more than 6 million deaths worldwide every year (World Health Organization, 2018). The use of cigarettes is highly associated with significant negative health outcomes and is known to substantially increase the risk for coronary heart disease, stroke, and the development of lung cancer (Centers for Disease Control, 2018). In addition to the extensive human cost cigarette use and the associated negative health outcomes impose a substantial economic burden both on smokers and the healthcare system at large. Smoking accounts for a combined cost of more than US $\$ 1.4$ trillion, or $1.8 \%$ of the world's annual gross domestic product, from both direct healthcare expenditure and lost productivity (Goodchild, 2018).

Although about 7 out of 10 smokers report a desire to quit, only 4 out of 10 will attempt to quit for at least one day. Successfully quitting often requires several attempts, as relapse is the most likely outcome of any quit attempt (Ockene, Mermelstein, Bonollo, Emmons, Perkins, Voorhees, \& Hollis, 2000). A variety of smoking cessation interventions exist, and current recommendations by the Clinical Practice Guidelines for Smoking Cessation (Fiore, 2008) suggest that medication-assisted therapy, such as varenicline (Chantix $\left.{ }^{\circledR}\right)$ and nicotine replacement therapy (NRT; i.e., nicotine patches and nicotine gum), ought to be utilized as first line treatments. Even though these approaches are among the most well-validated in the field of smoking cessation treatment, pharmacological aids only improve quit rates relative to placebo by about $5 \%$ to $23 \%$ at 6 months post quit (Etter \& Stapleton, 2006; García-Rodríguez, SecadesVilla, Florez-Salamanca, Okuda, Liu, \& Blanco, 2013). Furthermore, behavioral and counseling interventions report more modest and variable success (Gifford, Kohlenberg, Hayes, Antonuccio, Piasecki, Rasmussen-Hall, \& Palm, 2004; Salisbury-Afshar, 2018). Given the high rate of relapse across all treatment modalities, it is possible that current practices are generally ineffective at 
targeting and altering the variables that maintain smoking behavior among individual subjects. Therefore, the development of assessment devices designed to optimize treatment efficacy is needed in the current landscape of smoking cessation treatment.

In the field of applied behavior analysis (ABA), where there is a strong emphasis on addressing individual variability via personalized treatments, it is standard practice to conduct functional assessments to identify the behavioral functions maintaining unwanted behavior (Newcomer \& Lewis, 2004). In this case, the term function refers to the relationship between a behavior and its environmental consequences. The term "functional assessment" refers to a variety of techniques including indirect measures (e.g., survey), direct observation (e.g., observing the behavior in its natural environment), and experimental methods which seek to systematically manipulate the consequences of a target behavior to determine putative function (e.g. functional analysis). Functional assessment methodologies have been useful in treating unwanted behaviors such as self-injury, where the maintaining variables of problem behavior vary between individuals (i.e., for some individuals, problem behavior was maintained by attention and for others the behavior was maintained by escape from demands; Iwata, Dorsey, Slifer, Bauman, \& Richman, 1982). These findings suggest that although unwanted behavior may appear the same for different individuals (i.e., have the same form/topography), the underlying function of the behavior may be quite different. Furthermore, when treatments have been personalized to address the behavioral function (as identified by the functional assessment), outcomes improve considerably (Kuhn, DeLeon, Fisher, \& Wilke, 1999).

As with self-injurious and other unwanted behaviors, it is likely that smoking behavior is maintained by diverse functions. Further, current treatments are not recommended on the basis of functional assessment, and largely do not take into consideration these individual differences. For example, NRT, psychotherapy, and behavioral therapy might each target different behavioral functions related to smoking, however they are prescribed without precision. For some 
individuals, smoking might be reinforced primarily by the physiological effects of nicotine, whereas for other individuals smoking may be mainly reinforced as a means for stress reduction. Furthermore, social contingencies along with other conditioned stimuli associated with smoking add another dimension to the potential reasons why individuals may continue to smoke. It is also plausible that smoking is maintained by more than one function, requiring a multi-faceted approach towards treatment. The incongruence between what mechanisms are targeted by a treatment, and the individual's actual reasons for smoking, might prevent long-term abstinence. Indeed, Fagerström (2012) summarized the relevance of a more functional approach by recommending sensitivity towards not only the physiological contribution of nicotine in cigarettes, but also the role of the sensory stimuli and psychosocial dimensions.

Although experimental functional analyses are the most valid method of identifying behavioral functions of problem behaviors (Hanley, Iwata, \& McCord, 2003; Liu, Giza, \& Vrana, 1990), it may not be practical to experimentally manipulate the consequences of smoking. Although it is noted by Hanley et al. (2003) that indirect assessment methods fail to precisely assess putative reinforcers, they are a useful step in refining future analysis of behavior. Given the inherent difficulties associated with exerting experimental control over the consequences of cigarette use (i.e., physiological and social consequences of smoking), indirect assessment remains an important tool for tailoring treatment informed by contextual variables. Although a first step in a robust functional behavior assessment, the current research describes a functional assessment survey administered to smokers with the purpose of identifying putative reinforcers. To our knowledge, no previously developed measure has sought to identify the behavioral function of smoking (Axelrod, 1991), informed by the vast literature on functional assessment methodology discussed above. Although other measures have sought to assess similar variables related to the consequences of cigarette use (e.g., Brandon \& Baker, 1991; Piper, Piasecki, Federman, Bolt, Smith, Fiore, \& Baker, 2004), these measures generally emphasize sensory 
(smoking for the sensation) and physiological automatic reinforcers, and largely fail to account for socially mediated reinforcement derived from cigarette use. Although Piper et al. (2004) include a subscale relevant to socially mediated consequences of smoking, it fails to differentiate between mechanisms of positive and negative reinforcement. The FASTR contributes to the assessment of smoking behavior insofar as it seeks to account for the positive and negative social and automatic reinforcement derived from cigarette use. The FASTR further differs in its organization of putative motivations in its theoretical basis in the functional assessment literature. This is a critical difference as the valid and reliable identification of environmental variables implicated in cigarette use is essential for effective behavioral intervention.

In this vein, the proposed assessment device, the Functional Assessment for Smoking Treatment Recommendations (FASTR), seeks to measure the relevance of five behavioral functions, consistent with previous functional assessment approaches and informed by the field of ABA: (1) Automatic Positive Reinforcement, (2) Automatic Negative Reinforcement, (3) Social Positive Reinforcement, (4) Social Negative Reinforcement, and (5) Antecedent Stimuli. Positive reinforcement refers to maintenance of behavior because of the contingent addition of a stimulus after smoking (e.g., increased focus, pleasure from sensory stimuli associated with smoking, social interactions (Brandon \& Baker, 1991; Friedman, Lichtenstein, \& Biglan, 1985; Garey, Manning, Jardin, Leventhal, Stone, Raines, Pang, Neighbors, Schmidt, \& Zvolensky, 2018), whereas negative reinforcement refers to the maintenance of behavior because of the contingent removal of some stimulus, usually unpleasant, after smoking (e.g., removal of stress, break from work (Kassel, Stroud, \& Paronis, 2003; Pomerleau, Fagerström, Marks, Tate, \& Pomerleau, 2003). Automatic reinforcers are those that are not mediated by another individual but instead occur naturally as a function of smoking (e.g., increased focus, reduced stress, sensory stimuli) whereas social reinforcers are those that are explicitly controlled by interacting with another person (e.g., socializing with others while smoking, employer granting smoke break at work). 
Finally, for the fifth function, the importance of antecedent events has been widely established (Niaura, Rohsenow, Binkoff, Monti, Pedraza, Abrams, \& Shiffman, 1988; Shiffman, Dunbar, Li, Scholl, Tindle, Anderson, \& Ferguson, 2014; Shiffman, Paty, Gwaltney, \& Dang, 2004). Antecedent events can be conceptualized as either operant (i.e., discriminative stimuli that set the occasion for smoking) or as respondent (i.e., stimuli that elicit cravings and subsequent smoking because of being repeatedly paired with smoking and nicotine), or some combination of the two. The purpose of the FASTR is therefore to differentiate individual differences in behavioral function relevant to smoking, and subsequently guide treatment recommendations based on the individual's needs. This goal is analogous to recent Precision Medicine initiative, whereby treatments are guided by individual subject differences, with the goal of optimizing treatment outcomes (Bremer, Becker, Kolovos, Funk, van Breda, Hoogendoorn, \& Riper, 2018; Collins \& Varmus, 2015). The present study is a first step towards determining the validity and reliability of the FASTR. 


\section{Chapter 2}

\section{Method}

\section{Participants}

Participants were recruited through Amazon's Mechanical Turk (MTurk), Craigslist, and Facebook. Individuals below the age of 18 were excluded from participation, as were those who declined to provide consent to participation. Totaled across all platforms, 524 individuals completed the survey. Participants who failed to appropriately respond to probe questions (i.e., "For the following question, please select 'Strongly Disagree"”). Those who failed to appropriately respond were considered to have answered questions without reading carefully and were excluded from analysis (110 in total). In all, 414 individuals were included in the final analysis, with $220(56.46 \%)$ identifying as female, $196(47.34 \%)$ identifying as male, and 2 $(0.48 \%)$ identifying as transgender. The mean age of the sample was $38.02(\mathrm{SD}=11.2) . \mathrm{On}$ average, participants reported smoking an average of $9.15(\mathrm{SD}=6.96)$ cigarettes per day for a mean of 21.96 years $(\mathrm{SD}=11.97)$. Demographic information is presented for all participants in Table 1. All procedures were approved by the Rowan University Institutional Review Board.

\section{Procedures}

Participants recruited from MTurk were compensated approximately $\$ 1.00$ per 10 minutes of participation for successfully completing the survey, whereas those recruited from Craigslist and Facebook were entered into a lottery for one of three $\$ 50.00$ gift cards. All responders completed the survey through the Qualtrics survey platform. Participants were administered a psychosocial survey to gather basic demographic information and assess eligibility, and the Functional Assessment of Smoking Treatment Recommendations (FASTR) questionnaire. 
Table 1

Sample Demographics

\begin{tabular}{lc}
\hline & $\mathbf{n}(\mathbf{\%})$ \\
\hline Gender & $220(53.4)$ \\
Male & $192(56.5)$ \\
Female & $2(0.6)$ \\
Transgender & \\
Race & $11(2.7)$ \\
Asian & $45(10.9)$ \\
Black or African American & $15(3.6)$ \\
Mixed Race & $2(0.5)$ \\
Native American & $337(81.4)$ \\
White & \\
Ethnicity & $32(7.7)$ \\
Hispanic & $382(92.3)$ \\
Non-Hispanic & $119(29.7)$ \\
Income & $153(37.0)$ \\
Less than \$30,000 & $106(25.6)$ \\
\$30,000-\$59,999 & $36(8.7)$ \\
\$60,000-\$99,999 & \\
More than \$100,000 & $8(2.0)$ \\
Education & $54(13.0)$ \\
Less than H.S. diploma & $197(47.6)$ \\
High school diploma & $132(31.88)$ \\
Some college & $23(5.6)$ \\
Bachelor's degree & $\mathrm{M}=4.3, \mathrm{SD}=2.25$ \\
Advanced Degree & $\mathrm{M}=38.02, \mathrm{SD}=11.2$ \\
FTND & $\mathrm{M}=21.96(11.97)$ \\
Age & $\mathrm{M}=9.15(6.96)$ \\
Smoking duration (Years) & \\
Cigarettes per day & \\
\hline
\end{tabular}




\section{Measures}

Functional Assessment of Smoking for Treatment Recommendations (FASTR). The FASTR is a 30 -item questionnaire designed to assess the maintaining behavioral functions of smoking. Items were answered on a 5-point likert scale ranging from 1 (Strongly Disagree) to 5 (Strongly Agree). Each subscale ranged from 4 to 9 questions, and the full FASTR questionnaire can be found in Table 2. Item construction was informed by the experience of the authors in the field of smoking cessation research, qualitative assessment of smoking motivations, and by literature reviews of other measures in the field. Questions were constructed and selected based on their perceived conformity to behavioral functions commonly observed in the applied behavior analytic literature, and from previously validated measures in the smoking assessment literature.

Fagerström Test for Nicotine Dependence (FTND). The Fagerström Test for Nicotine Dependence (Heatherton, Kozlowski, Frecker, \& Fagerström, 1991) is a 6-item multiple-choice scale that seeks to assess the extent to which an individual is dependent on tobacco. Scoring ranges from 0 to 10, with higher scores suggestive of greater dependence.

\section{Statistical Analysis}

behavioral functions identified earlier: (1) automatic positive reinforcement, (2) automatic negative reinforcement, (3) social positive reinforcement, (4) social negative reinforcement, and (5) antecedent events. See Figure 1 for a visual representation of the initially specified model. After the initial model fitting, theoretically justifiable alterations were made to the structural equation model based on recommendations derived from modification indices. Such modifications are recommended to be made tentatively and with strong theoretical motivations, given the risk of overparameterization (Schreiber, Stage, King, Nora, \& Barlow, 2006). See Figure 2 for a visual representation of the re-specified model. Further pruning/merging of the subscales was not conducted for the same reasons. 
Table 2

Functional Assessment for Smoking Treatment Recommendations (FASTR)

1 I smoke because I like handling the cigarettes and cigarette container.

2 I smoke because I like watching the smoke as I exhale it.

3 I smoke because I like handling a lighter or matches

4 I smoke because I like the feel of smoke in my mouth and throat.

5 I smoke because I like the way it makes me feel around other people.

$6 \quad$ I smoke because I like the way people look at me when I am smoking.

7 I smoke because I like the way people interact with me when I am smoking.

$8 \quad$ I smoke to socialize with others

9 I smoke to help deal with anger.

10 I smoke to help deal with frustration and disappointment.

11 I smoke to cope with feeling sad or depressed.

12 I smoke to take my mind off of my worries

13 I smoke after my meals.

14 I smoke in my car.

15 I routinely smoke during, before, or after certain activities (sports, class, movies, $\mathrm{TV}$, etc.).

16 I smoke when I drink coffee.

17 I smoke to give myself a lift.

18 I smoke because it's relaxing.

19 I smoke to calm down.

20 I smoke to control my weight/appetite.

21 I smoke to help me concentrate.

22 I smoke to deal with boredom.

23 I feel more at ease around other people if I have a cigarette.

24 I smoke to help with cigarette urges/cravings.

25 I smoke when I drink alcohol.

26 I smoke when I need a break from something demanding.

27 I smoke when I need a break from other people.

28 I smoke to deal with stress.

29 I smoke without planning to - it's just part of my routine.

30 I smoke to avoid situations that make me uncomfortable.

Questions presented on a 5-point Likert scale: 1) Strongly Disagree, 2) Disagree, 3) Neither Agree/Disagree, 4) Agree, 5) Strongly Agree

The analysis was conducted in five stages: 1) preliminary modeling, 2) exploratory modification, 3) assessment of internal consistency, 4) preliminary assessment of differential subscale performance, and 5) divergent validity with nicotine dependence. First, the hypothesized confirmatory structural equation model was fit to the sample $(\mathrm{N}=414)$ using confirmatory factor 
analysis (CFA). The CFA models were conducted in R statistical software 3.4.3 (The R project for Statistical Computing, Vienna, Austria) using the 'lavaan' package (Rosseel, 2012). It was hypothesized that the dimensionality of the FASTR subscales would be congruent with the five The fit of the model was evaluated via the examination of the comparative fit index (CFI), Tucker-Lewis index (TLI), standardized root mean square residual (SRMR) and root mean square error of approximation (RMSEA). Fit indices were assessed according to recommendations by Hu and Bentler (1999), with TLI and CFI values between 0.90 and 0.95 indicating acceptable fit, SRMR values $<0.09$ indicating good fit, and an RMSEA between 0.06 and 0.08 indicating acceptable fit.

Internal consistency was assessed in the overall sample as well as in subsamples divided across demographic features. Given the low percentage of racially diverse participants, internal consistency was calculated for non-white $(n=73)$ and white subsamples $(n=337)$. Further, measure reliability was assessed among men $(n=196)$ and women $(n=220)$. Divergent validity was assessed by the correlations between FASTR subscales and the FTND. For exploratory purposes, percentages of participants who endorsed each of the five subscale functions were evaluated. An individual was determined to have 'endorsed' a subscale function if the mean of responses on that subscale was greater than or equal to 4 . Additionally, percentages of participants who endorsed more than one function were explored. 


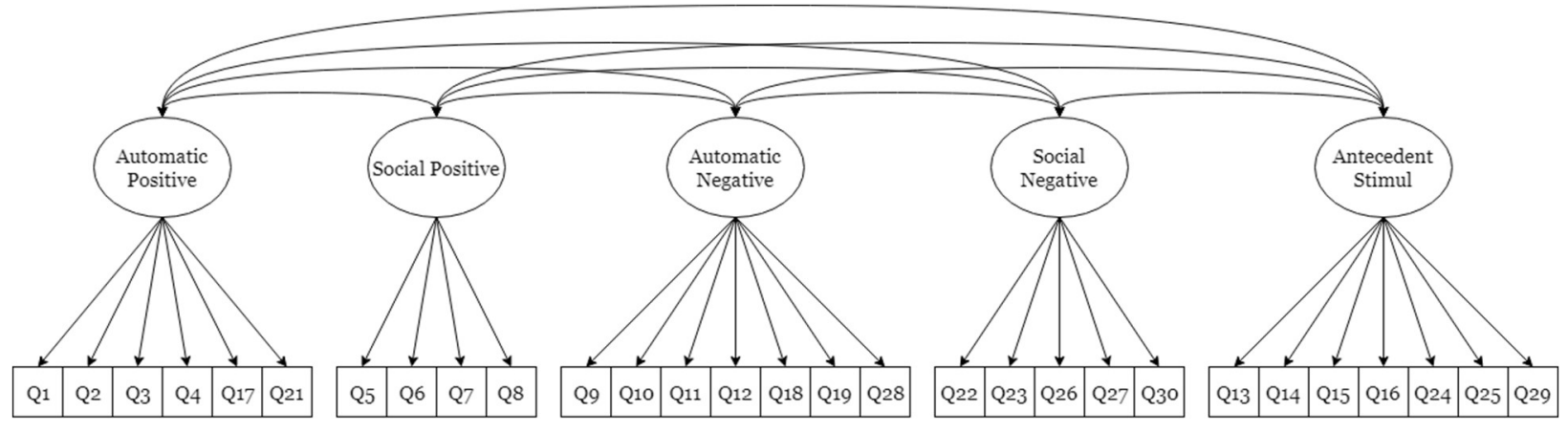

Figure 1. Model 1

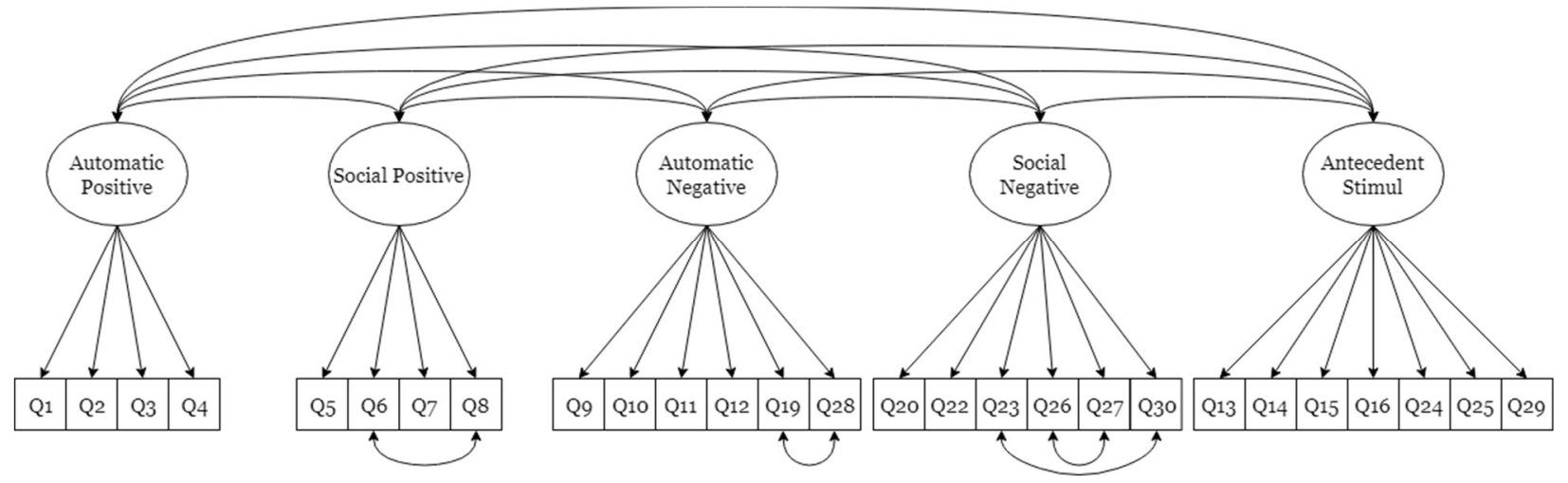

Figure 2. Model 2 


\section{Chapter 3}

\section{Results}

\section{Confirmatory Factor Models}

The initially proposed 5-factor model provided the following values for the examined fit indices: $\mathrm{CFI}=0.807, \mathrm{TLI}=0.787, \mathrm{SRMR}=0.102, \mathrm{RMSEA}=0.079(90 \% \mathrm{CI}=0.080,0.090)$. Questions 17, 18, and 21 were found to have low factor loadings $(<0.40)$ and were theoretically incongruent with other questions in their respective factors and were therefore removed from the model. Inspection of modification indices suggested large model misspecification caused by itemlevel error covariance among six pairs of items: Questions 6 and 8, 19 and 28, 23 and 30, 26 and 27 (see Table 3 and Table 4 for a summary of the modified model). It was deemed theoretically appropriate to allow the free estimation of these error covariances, and it resulted in improved fit across several indices. The modified model provided the following indices: $\mathrm{CFI}=0.908, \mathrm{TLI}=$ 0.896, $\mathrm{SRMR}=0.071, \mathrm{RMSEA}=0.059(90 \% \mathrm{CI}=0.053,0.064)$, confirming good model fit to the data.

\section{Internal Consistency}

Subscale reliability across the entire sample fell within an acceptable range (between $\alpha=$ 0.71-0.90). Reliability, examined among a number of subpopulations, was determined to be fairto-good (between $\alpha=0.71-0.90$ ). Among men and women, reliability ranged between $\alpha=0.72$ 0.90 and $\alpha=0.71-0.89$ respectively. Among white and non-white participants, reliability ranged between $\alpha=0.72-0.88$, and $\alpha=0.69-0.91$ respectively. See Table 5 for a summary of reliability (Cronbach's alpha) by subsample. 
Table 3

Scale Intercorrelations and Cronbach's Alpha for the Modified 5-Factor Model

\begin{tabular}{lccccc}
\hline Total Sample $(\mathrm{N}=414)$ & $\mathbf{1}$ & $\mathbf{2}$ & $\mathbf{3}$ & $\mathbf{4}$ & $\mathbf{5}$ \\
1. Automatic Positive & 0.78 & 0.65 & 0.18 & 0.38 & 0.18 \\
& $a$ & & & & \\
2. Social Positive & & $0.82^{a}$ & 0.19 & 0.46 & 0.07 \\
3. Automatic Negative & & $0.90^{a}$ & 0.78 & 0.53 \\
4. Social Negative & & & $0.78^{a}$ & 0.68 \\
5. Antecedent Stimuli & & & & $0.71^{a}$
\end{tabular}

Male $(\mathrm{n}=192)$

$\begin{array}{llllll}\text { 1. Automatic Positive } & 0.76 & 0.64 & 0.26 & 0.34 & 0.31\end{array}$

$\begin{array}{lllll}\text { 2. Social Positive } & 0.81^{a} & 0.39 & 0.51 & 0.18\end{array}$

3. Automatic Negative $\quad 0.90^{a} \quad 0.88 \quad 0.55$

$\begin{array}{lll}\text { 4. Social Negative } & 0.79^{a} & 0.71\end{array}$

5. Antecedent Stimuli $\quad 0.72^{a}$

Female $(\mathrm{n}=220)$

$\begin{array}{llllll}\text { 1. Automatic Positive } & 0.79 & 0.63 & 0.23 & 0.47 & 0.11\end{array}$

2. Social Positive $\quad 0.83^{a} \quad 0.10 \quad 0.46 \quad-0.02$

3. Automatic Negative $\quad 0.89^{a} \quad 0.67 \quad 0.52$

$\begin{array}{lll}\text { 4. Social Negative } & 0.76^{a} & 0.64\end{array}$

5. Antecedent Stimuli $0.71^{a}$

White $(\mathrm{n}=337)$

$\begin{array}{llllll}\text { 1. Automatic Positive } & 0.78 & 0.63 & 0.25 & 0.45 & 0.26\end{array}$

$\begin{array}{lllll}\text { 2. Social Positive } & 0.83^{a} & 0.24 & 0.49 & 0.08\end{array}$

3. Automatic Negative $\quad 0.90^{a} \quad 0.80 \quad 0.45$

5. Antecedent Stimuli

$0.77^{a} \quad 0.62$

Non-White $(\mathrm{n}=76)$

$\begin{array}{llllll}\text { 1. Automatic Positive } & 0.78 & 0.63 & 0.25 & 0.45 & 0.26\end{array}$

2. Social Positive

$\begin{array}{llll}0.83^{a} & 0.24 & 0.49 & 0.08\end{array}$

3. Automatic Negative

4. Social Negative

$\begin{array}{lll}0.90^{a} & 0.80 \quad 0.45\end{array}$

5. Antecedent Stimuli $0.72^{a}$

a. Cronbach's Alpha can be found on the diagonal. Pearson correlations found above diagonal. 
Table 4

Factor and Item Error Covariances of the Modified 5-Factor Model

\begin{tabular}{|c|c|c|c|c|}
\hline & Estimate & SE & p-value & $\begin{array}{l}\text { Standardized } \\
\text { Estimate }\end{array}$ \\
\hline \multicolumn{5}{|l|}{ Automatic Positive $\sim$} \\
\hline Social Positive & 0.642 & 0.037 & 0.000 & 0.642 \\
\hline Automatic Negative & 0.162 & 0.055 & 0.003 & 0.162 \\
\hline Social Negative & 0.370 & 0.060 & 0.000 & 0.370 \\
\hline Antecedent Stimuli & 0.037 & 0.064 & 0.565 & 0.037 \\
\hline \multicolumn{5}{|l|}{ Social Positive $\sim$} \\
\hline Automatic Negative & 0.143 & 0.053 & 0.007 & 0.143 \\
\hline Social Negative & 0.389 & 0.059 & 0.000 & 0.389 \\
\hline Antecedent Stimuli & -0.018 & 0.061 & 0.768 & -0.018 \\
\hline \multicolumn{5}{|l|}{ Automatic Negative $\sim$} \\
\hline Social Negative & 0.803 & 0.034 & 0.000 & 0.803 \\
\hline Antecedent Stimuli & 0.486 & 0.050 & 0.000 & 0.486 \\
\hline \multicolumn{5}{|l|}{ Social Negative $\sim$} \\
\hline Antecedent Stimuli & 0.702 & 0.050 & 0.000 & 0.702 \\
\hline \multicolumn{5}{|l|}{ Question 26 } \\
\hline Question 27 & 0.228 & 0.035 & 0.000 & 0.365 \\
\hline \multicolumn{5}{|l|}{ Question 6 } \\
\hline Question 8 & 0.407 & 0.056 & 0.000 & 0.481 \\
\hline \multicolumn{5}{|l|}{ Question 23 } \\
\hline Question 30 & 0.362 & 0.070 & 0.000 & 0.334 \\
\hline \multicolumn{5}{|l|}{ Question 19 } \\
\hline Question 28 & -0.213 & 0.056 & 0.000 & -0.424 \\
\hline
\end{tabular}

\section{Divergent Validity}

Correlations between the FASTR subscales and the FTND can be found in Table 5. Correlation indices between the measures were generally low (range $r=-0.049$ to $r=0.44$ ). The Antecedent Stimuli subscale showed the highest correlation with the FTND $(r=0.44)$.

\section{Subscale Performance}

Table 6 shows that Antecedent Stimuli was the most highly endorsed function of smoking ( $45 \%$ of participants), when endorsement was defined as a mean subscale score greater than or equal to 4 (i.e., an average response of 'agree'). Further, $32.61 \%$ of participants endorsed 
the Social Negative subscale. The least commonly endorsed function was Social Positive Reinforcement (4.11\%).

A plurality of participants (38.64\%) failed to endorse any function when the endorsement criterion was set to greater than or equal to 4 . Furthermore, of those who endorsed at least one function, $25.36 \%$ endorsed only one, whereas $35.99 \%$ of participants endorsed two or more functions. A small percentage of participants endorsed either $4(4.83 \%)$ or 5 functions $(1.93 \%)$.

Table 5

Correlations Between Modified FASTR Subscales and FTND Scores

\begin{tabular}{lcc}
\hline & \multicolumn{2}{c}{ FTND } \\
& $\mathbf{r}$ & $\mathbf{R}^{\mathbf{2}}$ \\
$\begin{array}{l}\text { Automatic } \\
\text { Positive }\end{array}$ & 0.027 & 0.001 \\
Social Positive & -0.049 & 0.002 \\
$\begin{array}{l}\text { Automatic } \\
\text { Negative }\end{array}$ & 0.207 & 0.043 \\
$\begin{array}{l}\text { Social Negative } \\
\text { Antecedent }\end{array}$ & 0.214 & 0.048 \\
Stimuli & 0.438 & 0.192 \\
\hline
\end{tabular}


Table 6

FASTR Subscale Endorsement

Subscale Endorsement*

Automatic Positive

Social Positive

Automatic Negative

Social Negative

Antecedent Stimuli n (\%) Endorsed

43 (10.39)

$17(4.11)$

$130(31.40)$

$135(32.61)$

187 (45.17)

\section{Number of Subscales}

Endorsed

No subscales $\geq 4$

One subscale $\geq 4$

Two subscales $\geq 4$

Three subscales $\geq 4$

Four subscales $\geq 4$

Five subscales $\geq 4$

$160(38.65)$

$105(25.36)$

$72(17.39)$

$53(12.80)$

$16(3.86)$

$8(1.93)$

*NOTE: Does not equal 100\% because some participants endorsed

more than one function. Mean subscale score was not calculated for those with missing responses $(n=68)$ 


\section{Chapter 4}

\section{Discussion}

The goal of the present study was to provide initial support for a functional approach to the assessment of cigarette use, informed by the vast literature on functional assessment for unwanted behavior (Newcomer \& Lewis, 2004). A novel survey was developed, taking in to consideration the five potential functions of smoking (i.e., social positive, social negative, automatic positive, automatic negative, and antecedent stimuli). Although the pre-modified model exhibited poor fit, the modified model showed substantial improvement after specification. CFI, TLI, RMSEA, and SRMR indices approached or exceeded acceptable thresholds. Given the convenient sampling method used in the study, it was deemed inappropriate to search for a best fitting model. Although the preceding analysis provided initial support for the validity of the 5factor structure for the FASTR, additional research is needed to confirm the findings of this analysis and to further explore its clinical utility.

Other assessments approach the measurement of smoking behavior with similar variables, the FASTR is novel insofar as it posits an approach congruent with a functional analytic approach to behavioral assessment intervention. The FASTR differs from other measures on the basis of theoretical organization. Other measures seek to assess the consequences of cigarette use. For example, the Wisconsin Inventory of Smoking Dependence Motives (Piper et al., 2004) (WISDM), the Smoking Consequences Questionnaire (Brandon \& Baker, 1991; Garey et al., 2018), the Smoking Effects Questionnaire (Rohsenow, Abrams, Monti, Colby, Martin, \& Niaura, 2003), and the Reasons for Smoking Scale (Tate \& Stanton, 1990), to varying degrees, seek to assess factors such as motivations, antecedents, and consequences of smoking. Other measures, such as the Fagerström Test for Nicotine Dependence (Fagerström, 2012; Heatherton et al., 1991), Michigan Nicotine Reinforcement Questionnaire (Pomerleau et al., 2003), the Questionnaire on Smoking Urges (Tiffany \& Drobes, 1991), and the Cigarette Dependence Scale 
(Velicer, DiClemente, Rossi, \& Prochaska, 1990) seek to assess levels of physiological and behavioral dependence. More recently, the Patient-Reported Outcomes Measurement Information System (PROMIS) Smoking Initiative has sought to implement a modern item response approach via item banking from a wide variety of assessment devices (Edelen, Stucky, Hansen, Tucker, Shadel, \& Cai, 2014; Hansen et al., 2014). The FASTR is unique, however, in that it applies a functional behavior analytic approach to the assessment of the putative reinforcers involved in the maintenance of smoking behavior. The functional analytic literature has demonstrated a high degree of success in altering rates of problem behavior. One important component of this success is the implementation of valid measurement of behavioral consequences, and the FASTR seeks to provide such a tool in order to facilitate personalized treatment recommendations.

Although only exploratory at this time, in the current study $62 \%$ of participants endorsed at least one of the five functions, and $36 \%$ endorsed two or more functions. The most commonly endorsed function was Antecedent Stimuli, but with only approximately half of participants endorsing this function, these data suggest that individual subjects are likely to need personalized recommendations for quitting that meet their unique needs. For example, individuals who endorse an automatic negative reinforcement function (e.g., I smoke to reduce cravings) may respond well to pharmacological interventions such as the patch and/or varenicline, whereas individuals who endorse an automatic positive reinforcement function may respond better to pharmacological interventions that also include sensory reinforcers, such as electronic cigarettes (although it should be noted that the clinical utility of electronic cigarettes is still unknown). For individuals who endorse a social function, it may be critical to identify effective support networks. In those cases, behavioral interventions that involve training non-smoking loved ones to provide social support for abstinence may be warranted. For individuals who endorse more than one function, a multi-faceted approach to treatment will likely be needed to address each individual function maintaining smoking. For example, if an individual endorses both automatic 
and social negative reinforcement functions, then NRT plus a social support intervention similar to that noted above may be needed. This type of personalized, multi-pronged treatment approach may be especially amenable to technology-delivered interventions, where the nature of the intervention could be personalized to the individual subject's specific function (Bock, Heron, Jennings, Morrow, Cobb, Magee, Fava, Deutsch, \& Foster, 2013; Businelle, Ma, Kendzor, Frank, Vidrine, \& Wetter, 2016). It is also possible that collecting information about the different functions, and/or the unique combination of functions, that maintain smoking for individuals may inform the development of novel interventions that have not yet been conceptualized in this way. Given the putative individual differences in the reasons for smoking identified in the current study, it is not surprising that interventions that are not personalized to the individual's reasons for smoking have experienced weak to moderate success.

Although the 5-factor model showed promising signs of initial construct validity in the current study, item-level analysis may also be useful in guiding treatment recommendations. For example, although an individual might score high on the Antecedent Stimuli subscale, individual response patterns may provide important information about how to adjust the environment to optimize treatment outcomes. For example, "I smoke in my car" might result in different recommendations than "I smoke when I drink alcohol," even though both items are part of the same subscale. Such intra-scale variability should be considered in future modeling of latent constructs measured by the FASTR. This was not done in the current study to avoid the artificial inflation of fit indices; thus, further validation is needed to assess novel factor structures. Further, if it is the case that item level analysis provides the most useful degree of clinical utility, then the extent to which the FASTR items might serve as a guide for a structured clinical interview, in line with a precision medicine approach, might be worthwhile.

The FASTR subscales successfully differentiated from traditional unidimensional measures of nicotine dependence, as evidenced by the low correlations between the FTND and 
FASTR subscales. This finding is consistent with what would be expected from a multidimensional assessment of cigarette use. The correlation was highest between the FTND and Antecedent Stimuli subscale, which might suggest that highly dependent individuals have greater control of smoking by antecedent events, possibly due to associative processes (Bevins \& Palmatier, 2004; Conklin, 2006).

No pronounced differences in reliability were observed between the full sample and subsamples. Reliability was lowest in the full sample for Antecedent Stimuli $a=0.71$, although it reached the recommended minimum threshold of $a=0.70$. Further analyses suggest that Automatic Negative and Antecedent Stimuli subscales were the most commonly endorsed in the current sample. Although these two subscales also had the most questions associated with them, endorsement was determined by averaging scores to control for these subsample differences. One limitation of the current study was that over $80 \%$ of the sample self-reported being non-Hispanic white. Future samples will seek greater racial and ethnic diversity.

In summary, the current study provides initial validity and reliability data for the FASTR, which is a novel approach towards identifying the reasons for smoking to personalize treatment recommendations. This goal is consistent with recent precision (i.e., personalized) medicine initiatives, of which genetic determinants of individual subject variability are typically the focus (Chen, Horton, \& Bierut, 2018). However, the current research suggests that environmental and behavioral determinants are also worth exploring to optimize treatment outcomes for smoking cessation (Khoury, Iademarco, \& Riley, 2016). Future research is needed to refine the FASTR, as well as to establish its predictive validity to determine whether treatment outcomes do in fact improve when they are matched to the individual's identified reasons for smoking. 


\section{References}

Axelrod, S. (1991). Smoking cessation through functional analysis. Journal of Applied Behavior Analysis, 24, 717-718.

Baker, T. B., Brandon, T. H., \& Chassin, L. (2004). Motivational influences on cigarette smoking. Annual Review of Psychology, 55, 463-491.

Brandon, T. H., \& Baker, T. B. (1991). The Smoking Consequences Questionnaire: The subjective expected utility of smoking in college students. Psychological Assessment: A Journal of Consulting and Clinical Psychology, 3(3), 484.

Bevins, R. A., \& Palmatier, M. I. (2004). Extending the role of associative learning processes in nicotine addiction. Behavioral and Cognitive Neuroscience Reviews, 3(3), 143-158.

Bock, B., Heron, K., Jennings, E., Morrow, K., Cobb, V., Magee, J., ... \& Foster, R. (2013). A text message delivered smoking cessation intervention: the initial trial of TXT-2-Quit: randomized controlled trial. JMIR mHealth and uHealth, 1(2).

Bremer, V., Becker, D., Kolovos, S., Funk, B., van Breda, W., Hoogendoorn, M., \& Riper, H. (2018). Predicting therapy success and costs for personalized treatment recommendations using baseline characteristics: Data-driven analysis. Journal of Medical Internet Research

Businelle, M. S., Ma, P., Kendzor, D. E., Frank, S. G., Vidrine, D. J., \& Wetter, D. W. (2016). An ecological momentary intervention for smoking cessation: evaluation of feasibility and effectiveness. Journal of Medical Internet Research, 18(12).

Center for Disease Control. Smoking \& Tobacco Use. (2018, July 10). Retrieved August 5, 2018, from https://www.cdc.gov/tobacco/data_statistics/fact_sheets/index.html

Chen, L. S., Horton, A., \& Bierut, L. (2018). Pathways to precision medicine in smoking cessation treatments. Neuroscience letters, 669, 83-92.

Collins, F. S., \& Varmus, H. (2015). A new initiative on precision medicine. New England Journal of Medicine, 372(9), 793-795.

Conklin, C. A. (2006). Environments as cues to smoke: implications for human extinction-based research and treatment. Experimental and clinical psychopharmacology, 14(1), 12.

Edelen, M. O., Stucky, B. D., Hansen, M., Tucker, J. S., Shadel, W. G., \& Cai, L. (2014). The PROMIS ${ }^{\circledR}$ smoking initiative: initial validity evidence for six new smoking item banks. nicotine \& tobacco research, 16(Suppl_3), S250-S260.

Etter, J. F., \& Stapleton, J. A. (2006). Nicotine replacement therapy for long-term smoking cessation: a meta-analysis. Tobacco control, 15(4), 280-285.

Fagerström, K.O. (2012). Determinants of tobacco use and renaming the FTND to the Fagerström Test for Cigarette Dependence. Nicotine \& Tobacco Research, 14, 75-78. doi:10.1093/ntr/ntr137

Fiore, M. (2009). Treating Tobacco Use and Dependence: 2008 Update: Clinical Practice Guideline. DIANE publishing.

Friedman, L. S.; Lichtenstein, E., Biglan, A. (1985). Smoking onset among teens: An empirical analysis of initial situations. Addictive Behaviors, 10, 1-13. 
García-Rodríguez, O., Secades-Villa, R., Flórez-Salamanca, L., Okuda, M., Liu, S. M., \& Blanco, C. (2013). Probability and predictors of relapse to smoking: results of the National Epidemiologic Survey on Alcohol and Related Conditions (NESARC). Drug and Alcohol Dependence, 132(3), 479-485.

Garey, L., Manning, K., Jardin, C., Leventhal, A. M., Stone, M., Raines, A. M., ... \& Zvolensky, M. J. (2017). Smoking Consequences Questionnaire: A reevaluation of the psychometric properties across two independent samples of smokers. Psychological Assessment, 30(5), 678-692.

Gifford, E. V., Kohlenberg, B. S., Hayes, S. C., Antonuccio, D. O., Piasecki, M. M., RasmussenHall, M. L., \& Palm, K. M. (2004). Acceptance-based treatment for smoking cessation. Behavior Therapy, 35(4), 689-705.

Goodchild, M., Nargis, N., \& Tursan d'Espaignet, E. (2018). Correction: Global economic cost of smoking-attributable diseases. Tobacco Control, 27, 478.

Hansen, M., Cai, L., Stucky, B. D., Tucker, J. S., Shadel, W. G., \& Edelen, M. O. (2013). Methodology for developing and evaluating the PROMIS ${ }^{\circledR}$ smoking item banks. Nicotine \& Tobacco Research, 16(Supplemental 3), S175-S189.

Heatherton, T. F., Kozlowski, L. T., Frecker, R. C., \& Fagerström, K. O. (1991). The Fagerström test for nicotine dependence: a revision of the Fagerstrom Tolerance Questionnaire. British Journal of Addiction, 86(9), 1119-1127.

Hu, L. T., \& Bentler, P. M. (1999). Cutoff criteria for fit indexes in covariance structure analysis: Conventional criteria versus new alternatives. Structural Equation Modeling: A Multidisciplinary Journal, 6(1), 1-55.

Iwata, B. A., DeLeon, I. G., \& Roscoe, E. M. (2013). Reliability and validity of the functional analysis screening tool. Journal of Applied Behavior Analysis, 46(1), 271-284.

Iwata, B. A., Dorsey, M. F., Slifer, K. J., Bauman, K. E., \& Richman, G. S. (1994). Toward a functional analysis of self-injury. Journal of Applied Behavior Analysis, 27(2), 197-209.

Kassel, J. D., Stroud, L., \& Paronis, C. (2003). Smoking, stress, and negative affect: Correlation, causation, and context across stages of smoking. Psychological Bulletin, 129, 270-304.

Khoury, M. J., Iademarco, M. F., \& Riley, W. T. (2016). Precision public health for the era of precision medicine. American Journal of Preventive Medicine, 50(3), 398.

Kuhn, D. E., DeLeon, I. G., Fisher, W. W., \& Wilke, A. E. (1999). Clarifying an ambiguous functional analysis with matched and mismatched extinction procedures. Journal of Applied Behavior Analysis, 32(1), 99-102.

Lancaster, T., \& Stead, L. F. (2017). Individual behavioural counselling for smoking cessation. Cochrane Database of Systematic Reviews, (3).

Newcomer, L. L., \& Lewis, T. J. (2004). Functional behavioral assessment: An investigation of assessment reliability and effectiveness of function-based interventions. Journal of Emotional and Behavioral Disorders, 12(3), 168-181.

Niaura, R. S., Rohsenow, D. J., Binkoff, J. A., Monti, P. M., Pedraza, M., \& Abrams, D. B. (1988). Relevance of cue reactivity to understanding alcohol and smoking relapse. Journal of Abnormal Psychology, 97(2), 133. 
Ockene, J. K., Mermelstein, R. J., Bonollo, D. S., Emmons, K. M., Perkins, K. A., Voorhees, C. C., \& Hollis, J. F. (2000). Relapse and maintenance issues for smoking cessation. Health Psychology, 19(1S), 17.

Piper, M. E., Piasecki, T. M., Federman, E. B., Bolt, D. M., Smith, S. S., Fiore, M. C., \& Baker, T. B. (2004). A multiple motives approach to tobacco dependence: the Wisconsin Inventory of Smoking Dependence Motives (WISDM-68). Journal of Consulting and Clinical Psychology, 72(2), 139.

Pomerleau, O. F., Fagerström, K. O., Marks, J. L., Tate, J. C., \& Pomerleau, C. S. (2003). Development and validation of a self-rating scale for positive-and negative-reinforcement smoking: The Michigan Nicotine Reinforcement Questionnaire. Nicotine \& Tobacco Research, 5(5), 711-718.

R Core Team. (2009). The R Project for Statistical Computing, Vienna, Austria.

Rohsenow, D. J., Abrams, D. B., Monti, P. M., Colby, S. M., Martin, R., \& Niaura, R. S. (2003). The Smoking Effects Questionnaire for adult populations: Development and psychometric properties. Addictive Behaviors, 28(7), 1257-1270.

Rose, J. E., \& Levin, E. D. (1991). Inter-relationships between conditioned and primary reinforcement in the maintenance of cigarette smoking. British Journal of Addiction, 86, 605-609.

Rosseel, Y. (2012). Lavaan: An R package for structural equation modeling and more. Version 0.5-12 (BETA). Journal of statistical software, 48(2), 1-36.

Schreiber, J. B., Nora, A., Stage, F. K., Barlow, E. A., \& King, J. (2006). Reporting structural equation modeling and confirmatory factor analysis results: A review. The Journal of Educational Research, 99(6), 323-338.

Shiffman, S., Dunbar, M. S., Li, X., Scholl, S. M., Tindle, H. A., Anderson, S. J., \& Ferguson, S. G. (2014). Smoking patterns and stimulus control in intermittent and daily smokers. PLoS One, 9(3), e89911.

Shiffman, S., Paty, J. A., Gwaltney, C. J., \& Dang, Q. (2004). Immediate antecedents of cigarette smoking: an analysis of unrestricted smoking patterns. Journal of Abnormal Psychology, 113(1), 166.

Tate, J. C., \& Stanton, A. L. (1990). Assessment of the validity of the Reasons for Smoking scale. Addictive Behaviors, 15(2), 129-135.

Tiffany, S. T., \& Drobes, D. J. (1991). The development and initial validation of a questionnaire on smoking urges. British Journal of Addiction, 86(11), 1467-1476.

Velicer, W. F., DiClemente, C. C., Rossi, J. S., \& Prochaska, J. O. (1990). Relapse situations and self-efficacy: An integrative model. Addictive Behaviors, 15(3), 271-283.

World Health Organization. (2018). Tobacco Fact Sheet. Retreived August 5, 2018, from http://www.who.int/news-room/fact-sheets/detail/tobacco. 